\title{
Simulated differences in 21 st century aridity due to different scenarios of greenhouse gases and aerosols
}

\author{
L. Lin ${ }^{1,2} \cdot$ A. Gettelman ${ }^{2} \cdot$ Q. Fu ${ }^{1,3} \cdot Y \cdot X^{2}$
}

Received: 30 June 2015 / Accepted: 24 January 2016 / Published online: 3 February 2016

(C) The Author(s) 2016. This article is published with open access at Springerlink.com

\begin{abstract}
Aridity, defined as the ratio of precipitation (P) to potential evapotranspiration (PET) over land, is critical to natural ecosystems and agricultural production. Global climate models project global decreases of P/PET (drying) in the 21 st century. We examine the uncertainty of aridity projections due to scenarios of greenhouse gases (GHGs) and aerosols with three sets of ensemble simulations from a single climate model, the Community Earth System Model (CESM1). Ensembles consist of two Radiative Concentration Pathways (RCPs) and a scenario with RCP-like GHGs but with aerosol precursor emissions and atmospheric oxidants fixed at the year 2005 level. Under a high GHGs emission scenario (RCP8.5), global land P/PET decreases (drying) by $6.4 \pm 0.8 \%$ in 2060-2080 relative to 1985-2005. A GHG mitigation scenario (RCP4.5) would reduce the drying (P/PET decrease) to $3.7 \pm 0.6 \%$. Although future aerosol emissions reduction would increase $\mathrm{P}$, we find that it has little impact on global aridity due to offsetting effects on PET. Regionally, deceasing aerosols can have significant effects and aerosol-induced P/PET changes are due to different factors across different regions. When normalized by global mean temperature response, GHGs decrease global land $\mathrm{P} / \mathrm{PET}$ by $2.7 \pm 0.6 \% /{ }^{\circ} \mathrm{C}$ and surface temperature changes dominate GHG-induced P/PET change.
\end{abstract}

This article is part of a Special Issue on "Benefits of Reduced Anthropogenic Climate ChangE (BRACE)" edited by Brian O’Neill and Andrew Gettelman.

Electronic supplementary material The online version of this article (doi:10.1007/s10584-016-1615-3) contains supplementary material, which is available to authorized users.

L. Lin

lzulinlei@126.com

1 College of Atmospheric Sciences, Lanzhou University, Lanzhou, China

2 National Center for Atmospheric Research, Boulder, CO, USA

3 Department of Atmospheric Sciences, University of Washington, Seattle, USA 


\section{Introduction}

Recent global warming has led to concern about future water cycle changes critical to agricultural production and stability of ecosystems. Aridity, or ratio of precipitation $(\mathrm{P})$ to potential evapotranspiration (PET) over land is a function of precipitation (P) and meteorological variables through PET. The variables that describe PET include the surface air temperature (SAT), available energy ( $\mathrm{Rn}-\mathrm{G})$, relative humidity $(\mathrm{RH})$, and wind speed at $2 \mathrm{~m}\left(\mathrm{u}_{2}\right)$ (Penman 1948). Previous studies (e.g., Nastos et al. 2013) sometimes used a definition of aridity employing PET that responds only to changes in temperature (e.g., Thornthwaite 1948). However, this PET is not suited to climate change studies [Sheffield et al., 2012]. So following Sherwood and Fu (2014)we will define P/PET by deriving PET from the physically-based Penman-Monteith algorithm (Shuttleworth 1993)to quantify the dryness of terrestrial climate.

Studies by Sherwood and Fu (2014) and Fu and Feng (2014) suggest that terrestrial climate overall will become drier in the future, despite an increase of precipitation in a warming climate. Based on global climate model output from the phase 5 of the Coupled Model Intercomparison Projected (CMIP5) (Taylor et al., 2012), Feng and Fu (2013), Dai (2013), Cook et al. (2014), Scheff and Frierson (2015), Lin et al. (2015) and Huang et al. (2015) projected drying over land in the 21st century with high greenhouse gas (GHG) emissions (Representative Concentration Pathway (RCP) 8.5) (Riahi et al., 2011). Feng and Fu (2013) found a smaller drying trend with a lower GHG level (RCP4.5) (Clarke et al., 2007). The $\mathrm{CO}_{2}$ concentration at 2100 is 540 parts-per-million in RCP4.5 and 940 parts-per-million in RCP8.5.

Four RCP scenarios with different GHG levels all assume a sharp reduction in aerosol emissions during the 21 st century due to mitigation of aerosol emissions. However, future aerosol emissions are highly uncertain as they are strongly influenced by economic activities and emissions controls. For example, $\mathrm{SO}_{2}$ emissions in Western Europe and the United States are now 75-90 \% below their peak in the 1970s due to emissions regulations (Smith et al., 2011). However, without significant current mitigation policies for $\mathrm{SO}_{2}$ emissions, $\mathrm{Asian} \mathrm{SO}_{2}$ emissions have continued to rise after the 1970's (Klimont et al., 2013). Thus, aerosol emissions are an anthropogenic radiative forcing, currently subject to mitigation policies in many developed countries, and likely to be mitigated in developing countries. Several studies have attempted to use idealized experiments to isolate climate impact of aerosols. Zhao et al. (2014) studied how dust aerosols impact global arid and semi-arid regions. As part of this special issue, $\mathrm{Xu}$ et al. (2015) estimated the aerosol impact on future heat extremes.

Here we focus on climate simulations from a single CMIP5 model, the Community Earth System Model (CESM1), under RCP8.5 and RCP4.5 to understand the avoided aridity impacts of lower GHG emissions. We also examine a scenario with RCP8.5 GHG emissions but constant (non-declining) aerosol emissions to better understand the effect of aerosol changes. We explore the roles of GHGs and aerosols in future projection of aridity and other key climate variables, and focus on understanding the extent to which future aridity differs between RCP8.5 and 4.5. Emission reductions that lower forcing from 8.5 to $4.5 \mathrm{~W} / \mathrm{m} 2$ can be accomplished in different ways, with different mixes of GHG and aerosol reductions. RCP8.5 and RCP4.5 each imply a specific mix of GHG/aerosol differences. One way to test the generality of the results to other emission reductions is to test whether the forcing changes due to aerosols vs. GHGs make a difference to avoiding impacts from changes in aridity. Lin et al. (2015) concerns projections of future aridity under RCP8.5, focused on the uncertainty of internal variability. Here we focus on distinguishing effects between greenhouse gases and 
aerosols, and distinguishing effects between different greenhouse gas scenarios, including a mitigation scenario. Details of the simulated responses of terrestrial aridity to black carbon and sulfate aerosols separately are treated by Lin et al. (2016). Finally, pre-industrial changes in terrestrial aridity for the period 850-2080 are discussed by Fu at al., (Changes in terrestrial aridity for the period 850-2080 from the Community Earth System Model, submitted to Journal of Geophysical Research: Atmospheres).

All simulations are from the same model (CESM) to eliminate model uncertainty due to initial conditions, and from multiple ensembles to sample internal variability uncertainty. We use a large ensemble of simulations to fully explore internal climate variability. Methods are described in Section 2. Future projections across scenarios are compared in Section 3 with the physical mechanisms explained in Section 4. We discuss the implications and conclusions in Section 5.

\section{Methods}

\subsection{Global climate model}

The Community Earth System Model (CESM1) is an earth system model consisting of atmosphere, land, ocean and sea-ice components that are linked though a coupler for exchanging state information and fluxes (Hurrell et al., 2013). The 21st century climate simulation using CESM1 are described in Meehl et al. (2013). CESM1 can reasonably reproduce observed temporal and spatial variability of aridity in the 20th century (Lin et al., 2015). Notably, the atmosphere component, the Community Atmosphere model (CAM) (Neale et al., 2010) now includes a comprehensive modal aerosol model (Liu et al., 2012), as well as a twomoment microphysics scheme (Morrison and Gettelman, 2008), which represents the direct and indirect effects of aerosols on clouds (Gettelman et al., 2010). Monthly data is used in this study.

\subsection{Model simulations}

(1) RCP8.5 Large Ensemble (LE). RCP8.5 LE is a 30-member ensemble of simulations from 1920 to 2100 with forcing from the RCP8.5 scenario. Each member of the ensemble is forced by the same GHG concentration and aerosol emission trajectory, but starts from randomly perturbed initial conditions in the atmosphere (Kay et al. 2015).

(2) RCP4.5 Medium Ensemble (ME). RCP4.5 ME uses the same strategies as the Large Ensemble but with a smaller ensemble size of 15. RCP4.5 ME is forced by the RCP4.5 scenario (Sanderson et al., 2015). RCP4.5 is a scenario with moderate mitigation that leads to lower GHG emissions and forcing than in RCP8.5. RCP4.5 and RCP8.5 have a similar future decrease in sulfur aerosols (the largest contribution to total aerosols) by about 60-70\% in 2070 relative to 2010 (Van Vuuren et al. 2011), so the effect of "GHG mitigation" is estimated by contrasting RCP4.5 simulations to RCP8.5.

(3) RCP8.5 with fixed aerosols (RCP8.5_FixA). The third set of simulations (15 ensemble members) is forced by the RCP8.5 scenario, except that aerosol precursor emissions and atmospheric oxidants are fixed at year 2005 levels (Xu et al., 2015). The aerosol concentrations can increase by $5-10 \%$ regionally by year 2100 even with fixed emission, 
as a result of climatic change. However, the aerosol optical depth change in the RCP8.5_FixA simulations between 2006 and 2080 is not significant in most regions (see supplement), therefore aerosol forcing is largely fixed in this simulation.

These three sets of simulation are utilized in three ways in this study. Firstly, by contrasting RCP8.5 simulations with RCP8.5_FixA, the effects of the sharp aerosol reduction from present-day level in RCP8.5 can be estimated. Secondly, climate differences between early and late 21 st century decades in RCP8.5_FixA are purely due to GHG forcing since aerosol emissions are fixed. Finally, the difference between the RCP8.5 and the RCP4.5 illustrates the impact of mitigation on aridity.

\subsection{PET calculation}

We obtain PET by the Penman-Monteith algorithm (Shuttleworth, 1993; Allen et al., 1998),

$$
P E T=\frac{(R n-G) \Delta(S A T)+\rho_{a} C_{p} e^{*}(S A T)(1-R H) C_{H} u_{2}}{\Delta(S A T)+\gamma\left(1+r_{s} C_{H} u_{2}\right)} / L_{v}
$$

where $\mathrm{Rn}$ is the net downward broadband radiation, $\mathrm{G}$ is the heat flux into ground, $\Delta$ is the slope of the saturation vapor pressure curve, $\rho_{\mathrm{a}}$ is the surface air density, $\mathrm{C}_{\mathrm{p}}$ is the specific heat of air, $\mathrm{e}^{*}$ is the saturated water vapor pressure, $\mathrm{C}_{\mathrm{H}}$ is the bulk transfer coefficient, $\mathrm{r}_{\mathrm{s}}$ is the bulk stomatal resistance under well-watered conditions, $\mathrm{L}_{\mathrm{V}}$ is the latent heat of vaporization for water, $\gamma$ is psychrometric constant. We use a $\mathrm{C}_{\mathrm{H}}$ of $4.8 \times 10^{-3}$ and a $\mathrm{r}_{\mathrm{s}}$ of $70 \mathrm{~s} / \mathrm{m}$, corresponding to a grasslike surface (Allen et al. 1998). From climate model output, we use the sum of sensible heat (SH) and latent heat (LH) to replace Rn - G (Scheff and Frierson, 2014). We adjust the CESM output wind speed from $10 \mathrm{~m}$ height to $2 \mathrm{~m}$ height using the equation of Allen et al. (1998).
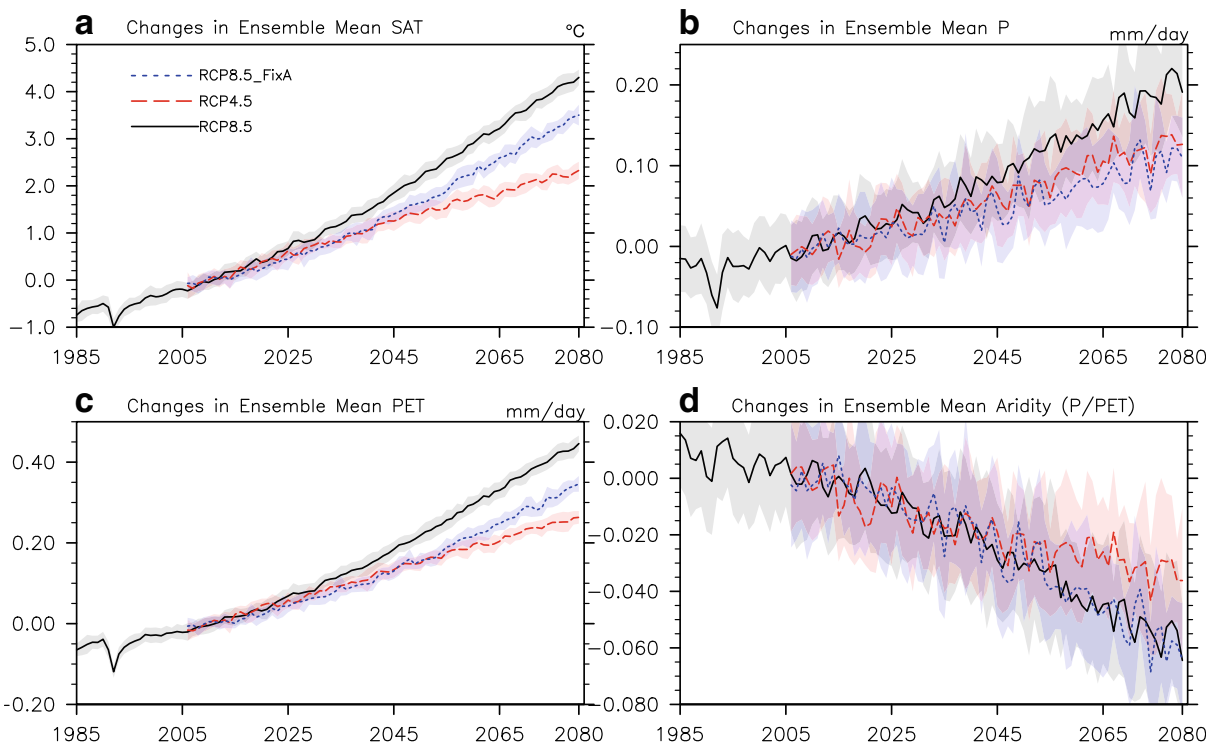

Fig. 1 Temporal variations of annual mean average Surface Air Temperature (SAT), Precipitation (P), Potential Evapotranspiration (PET) and P/PET anomalies in global land based on RCP8.5 (black), RCP4.5 (red) and RCP8.5_FixA (blue). The grey, red and blue shading denotes two standard deviation from 30 RCP8.5, 15 RCP4.5 and 15 RCP8.5_FixA simulations 


\section{Scenario dependence of aridity projections}

Figure 1 shows the future projections of SAT, P, PET and P/PET. All values are annual mean area-weighted averages over land between $60^{\circ} \mathrm{S}$ and $90^{\circ} \mathrm{N}$ (including Greenland). CESM1 projects a strong global warming $\left(2-4{ }^{\circ} \mathrm{C}\right)$ by 2060-2080 from present-day (1985-2005) under all three scenarios (Fig. 1a). The analysis ends in 2080 because the RCP4.5 ME ends in 2080. In addition to global land, we select seven regions for further analysis: Eastern USA, Europe, Eastern China, Eastern Brazil, Southern Africa, Northern Australia and India (domains shown in boxes of Fig. 3). Figure 2 shows the regional averages of projected changes in SAT, P, PET and P/PET over land for 2060-2080 relative to 1985-2005. The changes of P, PET and P/PET are shown as a percentage change.

All three scenarios project decreases in global P/PET (i.e. drying, Fig. 1d), as the increases in PET dominate the increases in precipitation. The drying in RCP4.5 (4\% by 2060-2080) is less severe than RCP8.5 (7 \%). The ensemble mean P/PET change under RCP4.5 and RCP8.5 is significantly different at the $95 \%$ level based on estimating the difference in two sample means of 2060-2080 average, and using each ensemble member to estimate the standard deviation of decadal means for a two-sided t-test. The standard deviation of the decadal means is much smaller than the standard deviation of each year shown in Fig. 1. Similar avoided impacts on global P/ PET have been seen in previous studies (Feng and Fu, 2013) using the entire CMIP5 ensemble.

The GHG mitigation from RCP8.5 to RCP4.5 (i.e., moving from the black curve to the red curve in Fig. 1) lowers the temperature projection due to smaller GHGs radiative forcing. Fixing present-day aerosols in RCP8.5 (black to blue) lowers the temperature projection due to a larger negative forcing from constant present-day aerosols. Quantitatively, RCP8.5 projects a $4.1 \pm 0.1{ }^{\circ} \mathrm{C}$ increase in SAT over global land for 2060-2080 relative to 1985-2005, while RCP4.5 projects $2.4 \pm 0.1{ }^{\circ} \mathrm{C}$ and RCP8.5_FixA $3.3 \pm 0.1{ }^{\circ} \mathrm{C}$ (Fig. 2a). Xu et al. (2015) discussed the implications of such avoided warming on heat extremes. Precipitation generally increases more in RCP8.5 than RCP4.5 (Fig. 1b). But the changes of precipitation are not consistent across regions as with temperature, which is a consequence of different precipitation trends in the high latitudes, tropics and sub-tropics (Stocker et al., 2013). Increases in PET in RCP4.5 (Fig. 1c), similar to temperature, are only about half in RCP8.5, since PET is mostly defined by temperature and humidity.

A major finding of this study is that there is no notable difference in P/PET projection between RCP8.5 and RCP8.5_FixA (Fig. 1d). This is due to compensation effects: aerosols induce a stronger suppression of precipitation than with GHG mitigation (Fig. 1b), but they also have a less cooling effect (Fig. 1a). Also Rn decreases, thus reducing PET (details in section 4.2.1). Although aerosols have no significant impact global mean P/PET (Fig. 1d), the regional impact can be significant (Fig. 2d), especially over Europe and Southern Africa. Regionally, GHG mitigation has a stronger impact than present-day aerosols on SAT over all selected regions (Fig. 2a), especially over Southern Hemisphere ( $\mathrm{SH}$ ) regions where presentday aerosol emissions are already low.

Globally, both GHG mitigation and present-day aerosols damp the future precipitation increases (Fig. 2b, i.e. $5.7 \pm 0.5 \%$ under RCP4.5 and $4.6 \pm 0.6 \%$ under RCP8.5_FixA while $8.1 \pm 0.7 \%$ under RCP8.5, by 2060-2080 relative to 1985-2005). The reduction is robust across all ensemble members. However, this comparison is somewhat arbitrary, since the magnitude of the change is specific to the size of the GHG and aerosol forcing perturbation. The real issue is what is the sensitivity per unit of forcing, or more relevant perhaps, per unit global mean temperature change, which we will further examine in section 4. 

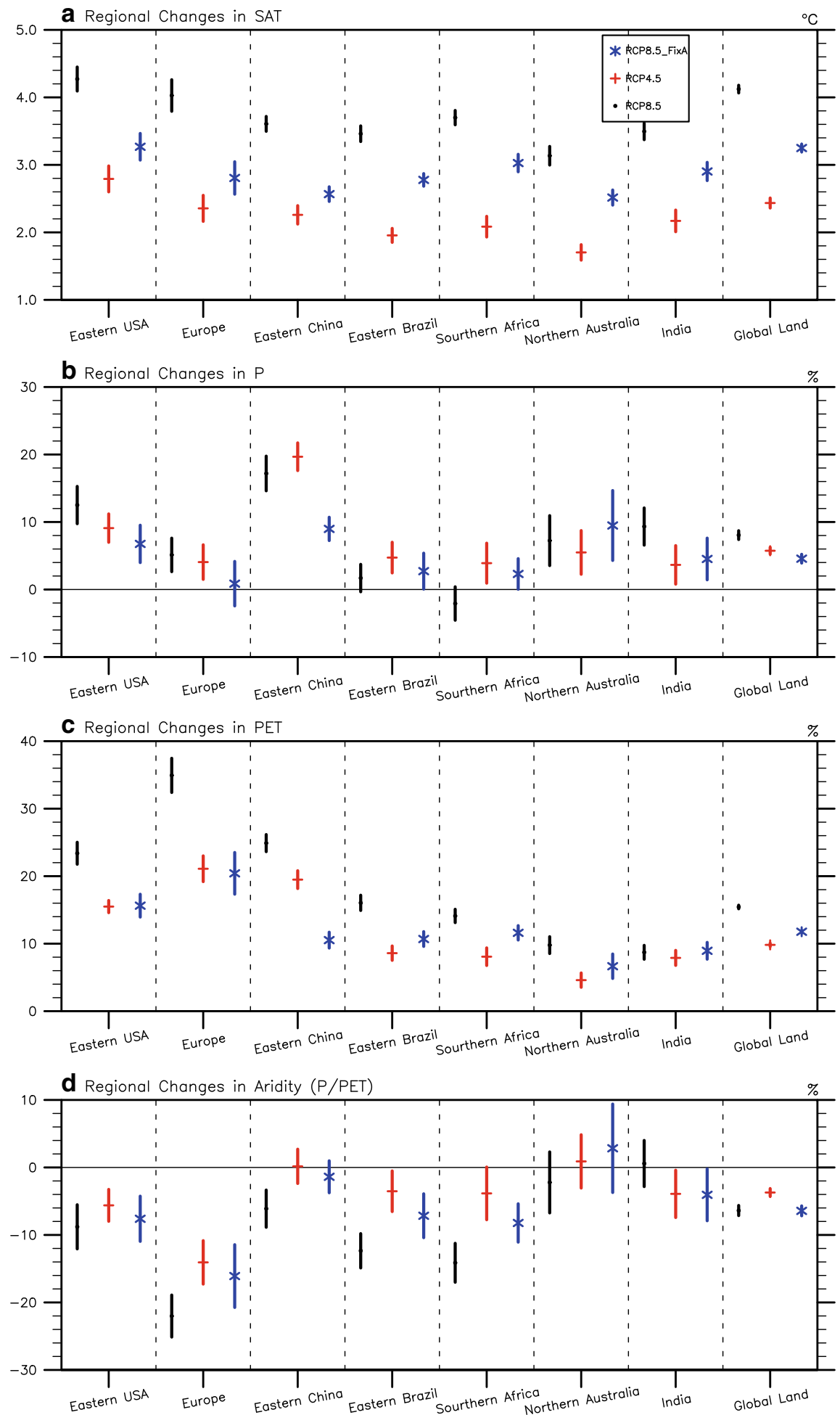
Fig. 2 Area average of Projected changes in Surface Air Temperature (SAT), Precipitation (P), Potential Evapotranspiration (PET) and P/PET for 2060-2080 relative 1985-2005 from RCP8.5 (black), RCP4.5 (red) and RCP8.5 FixA (blue). The black, red and blue error bar denotes two standard deviation of RCP8.5, RCP4.5 and RCP8.5_FixA ensembles. The eight selected regions are the Eastern USA, Europe, Eastern China, Eastern Brazil, Southern Africa, India, Northern Australia and Global Land (see the boxes of Fig. 3)

Present-day aerosols induce a larger precipitation reduction than GHG mitigation (Fig. 1b), despite a smaller cooling effect (Fig. 1a). This is illustrated as a larger hydrological sensitivity (\% of precipitation change per degree of warming) in Fig. $3 b$ due to aerosols (See section 4). The larger sensitivity due to aerosols is consistent with previous studies (Ramanathan et al., 2001; Shiogama et al., 2010). Present-day aerosol suppression of precipitation is strong over most Northern Hemisphere land, but weak in SH regions (Fig. 2b). The cooling from GHG mitigation in general damps precipitation changes. However, RCP4.5 has a larger precipitation increase than RCP8.5 over some regions (Eastern China, Eastern Brazil and Southern Africa) (Fig. 2b), which could be related to the regional precipitation changes due to small differences in aerosol levels between RCP8.5 and RCP4.5 (see Supplements of Xu et al., 2015).

GHG mitigation and present-day aerosols tend to damp projected increases in PET (Fig. 1c). Globally, RCP8.5 simulations project $15.4 \pm 0.3 \%$ increases in PET, $9.8 \pm 0.2 \%$ for RCP4.5 and $11.8 \pm 0.2 \%$ for RCP8.5_FixA (2060-2080 relative to 1985-2005). Regionally, present-day aerosols reduce PET less than GHG-mitigation except in Europe and Eastern China (Fig. 2c). In Section 4, we examine in details the physical parameters that contribute to PET changes.

Both RCP8.5 and RCP8.5_FixA ensembles have a $6.4 \%$ decrease in global average P/PET for 2060-2080 relative to 1985-2005. Over the same period, the RCP4.5 ensemble has a $4 \%$ decrease in P/PET (Fig. 2d). The aerosol impact on P/PET is minimal due to a cancellation of the precipitation reduction and PET reduction. The GHG mitigation slows down the projected increasing aridity (decreasing P/PET) under RCP8.5 due to a smaller reduction in P than PET (Fig. 2b and 2c). GHGs mitigation reduces drying in most land regions and has a stronger impact than present-days aerosols in the five of seven study areas (Fig. 2d). Present-day aerosols tend to decrease P/PET in India (Fig. 2d), because aerosols change PET slightly in India but suppress the precipitation.

In next section, we contrast the regional distributions and mechanisms between GHGs and aerosols.

\section{Normalized change in SAT, P, PET and P/PET due to GHGs and aerosols}

Since the absolute value of temperature response is larger for GHGs mitigation than presentday aerosols ( 1.7 vs. $0.8^{\circ} \mathrm{C}$ ), we normalize the climate response with respect to the global mean SAT change with each case. Thus, we can contrast the contributions to PET and P/PET due to the difference in GHG and aerosols. Note that aerosol emissions are regional and will depend on the scenario, but they have known source regions. Thus, the aerosol sensitivities are likely to be only weakly dependent on the scenario since most aerosol scenarios have similar reductions in similar regions (van Vuuren et al., 2011).

We also investigated GHG-induced changes alone by contrasting the averages of the RCP8.5_FixA for the years 2030-2050 and 2060-2080. This yields the climate changes purely due to GHGs. Fu and Feng (2014) showed using $1 \%$ year $\mathrm{CO}_{2}$ increase CMIP5 experiments (multi-model mean) that the increase in $\mathrm{P}$ averaged over land is $1.4 \% /{ }^{\circ} \mathrm{C}$, while 

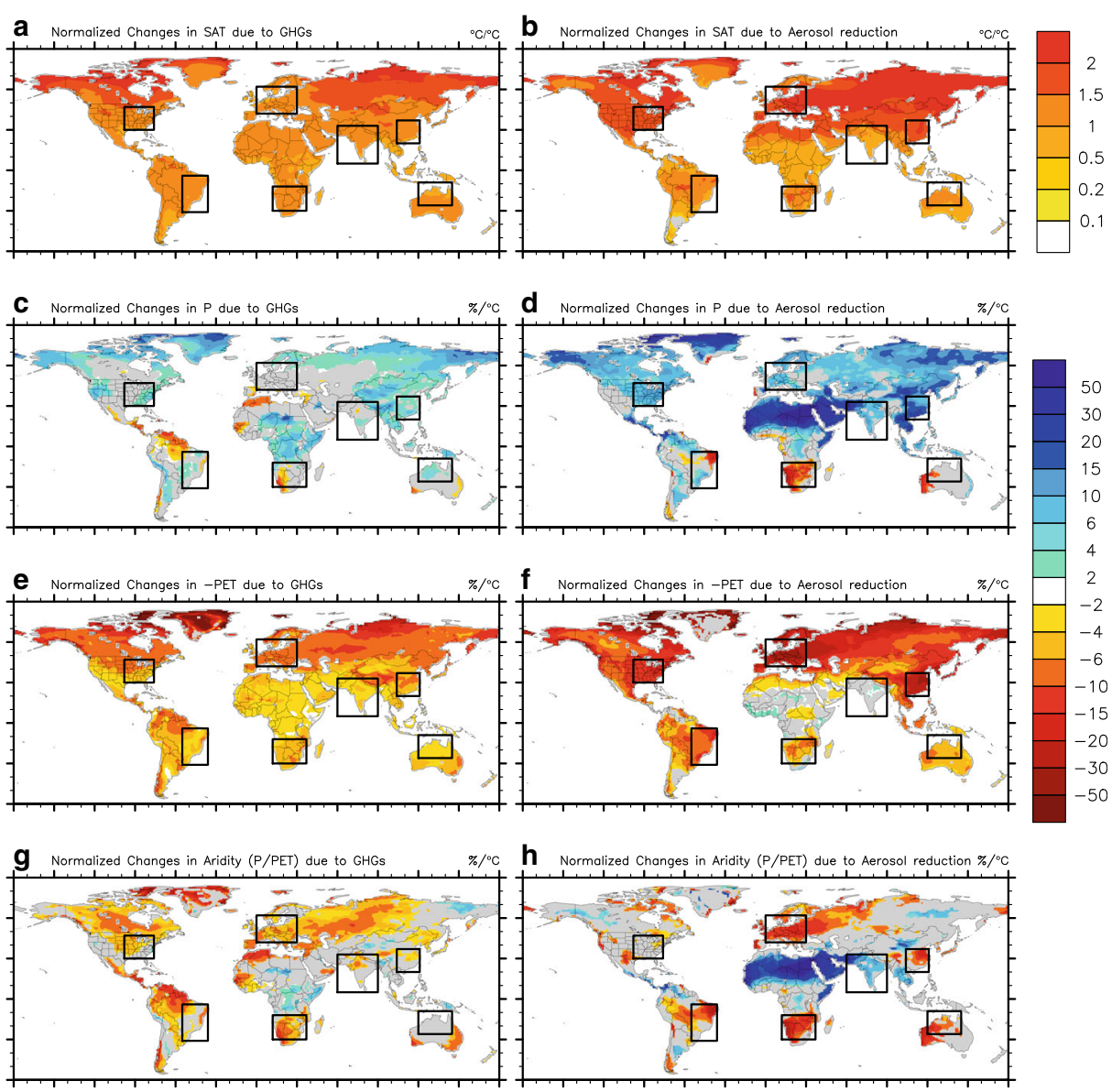

Fig. 3 The change of Surface Air Temperature (SAT), Precipitation (P), Potential Evapotranspiration (PET) and P/PET due to GHGs (contrasting the averages of the RCP8.5_FixA for the years 2030-2050 and 2060-2080) and Aerosols (taken as the differences between the averages RCP8.5_FixA and RCP8.5 for the years 2060-2080), scaled by global mean surface air temperature changes. Gray regions do not have statistically significant changes based on a $95 \%$ confidence interval from a two-sided t-test

PET increased at $4.6 \% /{ }^{\circ} \mathrm{C}$, leading to an P/PET decrease (i.e., drying) by $2.9 \% /{ }^{\circ} \mathrm{C}$. We find $1.7 \% /{ }^{\circ} \mathrm{C}$ for $\mathrm{P}$ and $4.9 \% /{ }^{\circ} \mathrm{C}$ for PET, yielding a P/PET decrease of $2.7 \% /{ }^{\circ} \mathrm{C}$ very similar to the normalized changes due to $\mathrm{CO}_{2}$ alone shown in Fu and Feng (2014). Aerosol reductions impact $\mathrm{P}\left(6.1 \% /{ }^{\circ} \mathrm{C}\right)$ and $\mathrm{PET}\left(6.4 \% /{ }^{\circ} \mathrm{C}\right)$ more than $\mathrm{GHG}$ changes, thus aerosols impact the $\mathrm{P} /$ PET much less than GHGs $\left(0.1 \% /{ }^{\circ} \mathrm{C}\right.$ for aerosols, while $-2.7 \% /{ }^{\circ} \mathrm{C}$ for $\left.\mathrm{GHGs}\right)$.

\subsection{Regional patterns}

Figure 3 shows the global distributions of normalized changes in SAT, P, PET and P/PET due to GHGs and aerosol reductions. The spatial pattern of changes in P, PET and P/PET due to GHGs (Fig. 3c, e and g) is similar to the multi-model mean patterns in Fu and Feng (2014) (Fig. 2) forced by $\mathrm{CO}_{2}$ alone. Per degree of global mean temperature change, the land warms by $1.5 \pm 0.1{ }^{\circ} \mathrm{C}$ due to aerosol reductions and $1.3 \pm 0.03{ }^{\circ} \mathrm{C}$ due to GHGs. Relative to GHGs, 
aerosol reductions cause more warming in the $\mathrm{NH}$ mid-latitudes, and less warming in the $\mathrm{SH}$ (Fig. 3a and b).

The patterns of precipitation change caused by GHGs and aerosol reductions are quite different. The spatial heterogeneity of precipitation response to aerosols arises from several factors. Aerosols serve as cloud condensation nuclei and thus have a substantial effect on cloud droplet formation and eventually precipitation production (Rosenfeld et al., 2008; Huang et al., 2014). Small variations or changes in the amount, altitude, physical thickness, and/or microphysical properties of clouds due to human influences can then alter the hydrological cycle (Huang et al., 2006a, 2006b). Overall, aerosols appear to induce larger $\mathrm{P}$ change per degree of warming (blue area in Fig 3d). Lambert and Allen (2009) also found greater sensitivity of P to aerosols than GHGs. Note that large and significant percentage changes occur over some regions with low precipitation (i.e. the Sahara).

The PET pattern due to GHGs is more spatially uniform (Fig. 3.e) than that due to aerosol reductions (Fig. 3.f). Aerosol reductions suppress the increasing PET over parts of Africa and India, despite warming temperatures there. GHGs induce drying (Fig. 3.g) over most land regions except Africa and Northeastern Asia, while aerosols have a larger impact on Eastern Brazil, Europe, Northern Africa, Southern Africa, Southern China and Western Northern Australia (Fig. 3.h). Opposite signs of P/PET change occur between GHGs and aerosol reductions in northern Eastern Brazil and India, but for different reasons. For Eastern Brazil, P/PET changes are due to different sign in precipitation change between GHGs and aerosol reductions. For India, P/PET changes are due to different sign in PET changes. In the reduced aerosol case, even over places with decreasing P/PET, P/PET decreases can be caused by either decreasing $\mathrm{P}$ (Northern Australia) or increasing PET with a small P increase (e.g. parts of China).

Figure 4 summarizes the normalized changes over selected regions in Fig. 3. Normalized changes of SAT and PET due to GHGs are of the same sign and similar magnitude across regions (red bars). Even though the precipitation change in Southern Africa is negative, the aridity change there is similar to other regions. Normalized changes due to aerosol reductions (blue bars in Fig. 4) have different magnitudes across these regions, especially between the $\mathrm{NH}$ and $\mathrm{SH}$. $\mathrm{NH}$ temperature changes faster than the global mean (except India). The NH temperature change is notable in the reduced aerosol case. Aerosol reductions induce positive precipitation changes over NH regions but negative precipitation changes over the SH (Fig. 4.b). This shift is in addition to the larger total rainfall change. The PET changes due to aerosols are larger than from GHGs over the NH (e.g., $20 \%$ larger over Europe and Eastern China) except over India (near zero). P/PET changes due to GHGs are of the same sign, but not the same magnitude in seven study areas (e.g. $-0.2 \pm 3.8 \% /{ }^{\circ} \mathrm{C}$ over Northern Australia but $-5.0 \pm 2.6 \% /{ }^{\circ} \mathrm{C}$ over Europe). Aerosol reductions cause larger normalized P/PET change than GHGs over these seven regions and cause positive $\mathrm{P} /$ PET change in India while negative change over the other six regions (Fig. 4d). The near-zero global aridity change due to aerosols is mainly driven by increasing $\mathrm{P} / \mathrm{PET}$ over northern Africa (Fig. 3h).

In summary, the normalized change of T, P, PET and P/PET due to GHGs are more homogeneous in space than those due to aerosols. Despite of having minimal impact on global aridity, aerosols cause more regional normalized P/PET change than GHGs. 

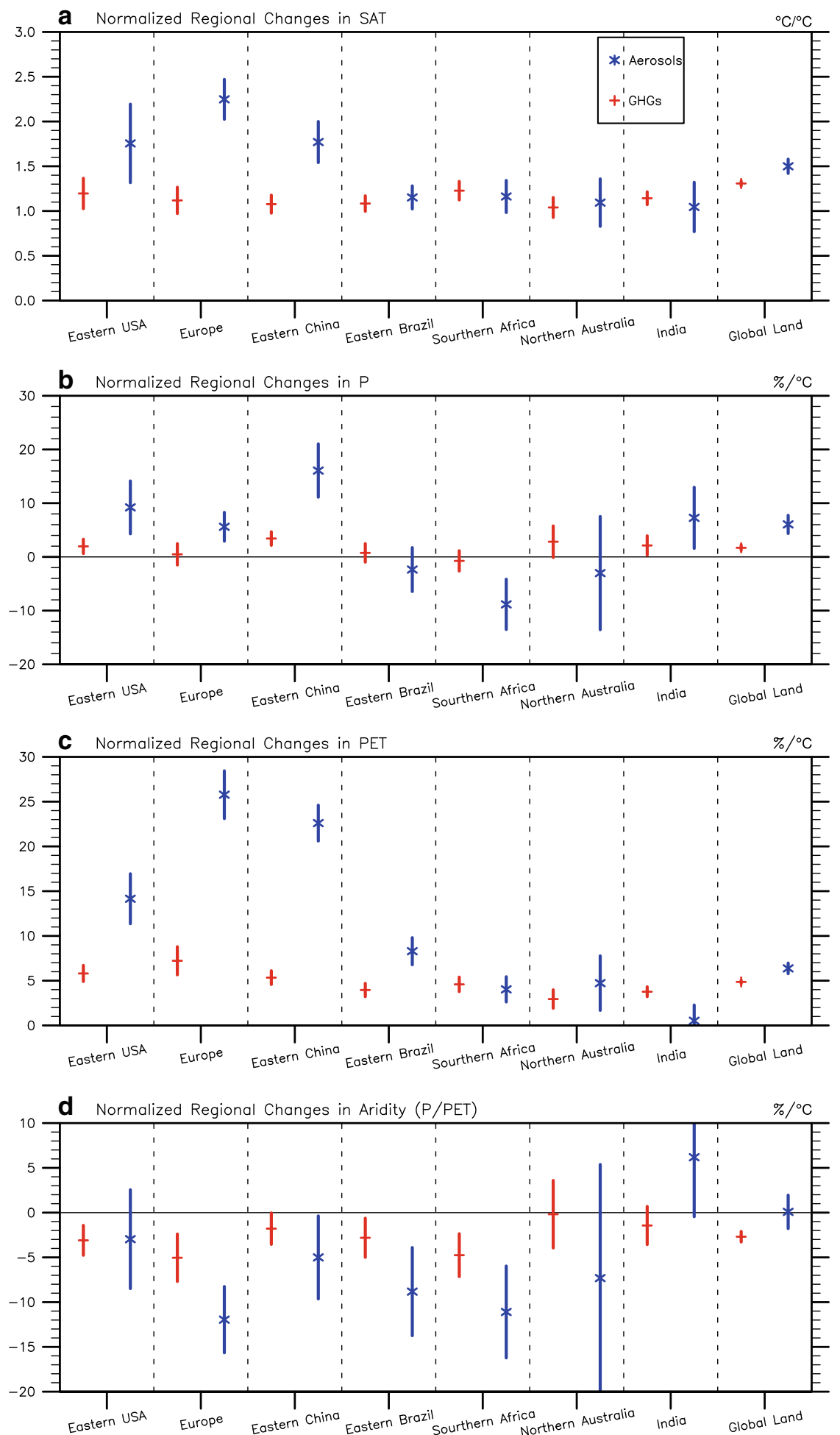
Fig. 4 Area average of normalized changes of Surface Air Temperature (SAT), Precipitation (P), Potential Evapotranspiration (PET) and P/PET due to GHGs (contrasting the averages of the RCP8.5_FixA for the years 2030-2050 and 2060-2080) and Aerosols (taken as the differences between the averages RCP8.5 FixA and RCP8.5 for the years 2060-2080). The red (blue) error bar denotes two standard deviation of GHGs (Aerosols)

\subsection{Physical factors determining different normalized change due to GHGs and aerosols}

\subsubsection{Changes in PET}

To explore how GHGs and aerosols impact PET differently, we use equation (1) to quantify the relative contributions of changes in SAT, relative humidity $(\mathrm{RH})$, wind speed $\left(\mathrm{u}_{2}\right)$ and available energy $(\mathrm{Rn}-\mathrm{G})$ to the total percentage changes in PET over global land. See Appendix A of Fu and Feng (2014) for details on the method of deriving the individual contributions. The change in PET due to GHGs is dominated by SAT changes (64.2 $\pm 1.6 \%)$, while the changes in RH and available energy also make appreciable contributions $(14.5 \pm 2.3 \%$ and $19.7 \pm 1.5 \%$, respectively). The partitioning of relative contributions broadly agrees with $\mathrm{Fu}$ and Feng (2014), except for a larger contribution of $\mathrm{u}_{2}$ of $1.5 \pm 0.8 \%$ (0 \% in Fu and Feng (2014)). This also supports Scheff and Frierson (2014), which showed warmer temperature increases PET due to increasing vapor pressure deficit and the Clausius-Clapeyron slope. The larger sensitivity to SAT for the GHG case holds in all selected regions.

For the aerosol case, the available energy contribution to global PET change is as large as the SAT contribution $(41.3 \pm 5.8 \%$ and $58.0 \pm 2.6 \%$, respectively). The available energy contribution can be even larger than the SAT contribution in NH regions with high aerosol loading. The available energy contribution is mainly caused by net shortwave radiation at the surface. $\mathrm{RH}$ and $\mathrm{u}_{2}$ do not impact PET significantly at the global scale $(0.4 \pm 7.6 \%$ and $0.3 \pm 1.3 \%$, respectively), but regionally $\mathrm{RH}$ or/and $\mathrm{u}_{2}$ make appreciable contributions over Europe, Eastern Brazil, Southern Africa, Northern Australia and India. In India, aerosol effect to PET through SAT cancel out that through RH (not shown), leading to minimal changes in PET.

\subsubsection{Changes in P/PET}

Similarly, we provide the details in Appendix A of this study on the method of deriving the individual contributions of changes in SAT, RH, $\mathrm{u}_{2}, \mathrm{Rn}-\mathrm{G}$ and $\mathrm{P}$ to total percentage changes in P/PET globally and over the seven study areas.

Figure 5 shows the relative contributions of changes in SAT, RH, $\mathrm{u}_{2}, \mathrm{Rn}-\mathrm{G}$ and $\mathrm{P}$ to the total percentage changes in P/PET over the seven study areas and global land. To highlight the different magnitudes, all relative contributions are displayed as positive numbers in Fig. 5, regardless of the actual sign. The change in P/PET over global land due to GHGs is dominated by SAT change $(47.9 \pm 3.2 \%)$, while the changes in P, RH and Rn - G contribute $(26.0 \pm 6.6 \%, 10.4 \pm 2.6 \%, 14.5 \pm 0.8 \%$, respectively). Fu and Feng (2014) showed that SAT changes dominate the global aridity changes in $\mathrm{CO}_{2}$ only case. Regional responses to global temperature change, however, could be different. Precipitation causes the largest aridity change due to GHGs in Eastern China and Northern Australia, although temperature dominates in the other five study areas except India. Similarly, Gao et al. (2015) argued that precipitation changes dominate GHG induced aridity change in Tibetan Plateau. 
In the aerosol case, the greatest impact to global P/PET change is from $\mathrm{P}(49.7 \pm 7.7 \%)$, and SAT and Rn - G contribute (28.6 $\pm 3.6 \%$ and $20.5 \pm 1.3 \%$, respectively). Regionally, P causes the largest change of P/PET in all study areas except Europe and Eastern Brazil. RH is important in Europe, Eastern Brazil, Southern Africa, Northern Australia and India.

Thus, changes in P/PET due to GHGs are dominated by SAT and P. Aerosol induced P/PET change is not caused by the same physical factors across different regions.

\section{Discussions and conclusions}

We find that under RCP8.5 (a high GHG emission scenario), the global annual mean P/PET over global land decreases (i.e. drying) by $6.4 \pm 0.8 \%$ in $2060-2080$ relative to $1985-2005$, consistent with earlier studies. In RCP4.5 (a mitigation scenario) the P/PET decrease is only $3.7 \pm 0.6 \%$. The ensemble variance from a single model is small compared to the difference between these two scenarios, indicating the difference between scenarios is significant. The
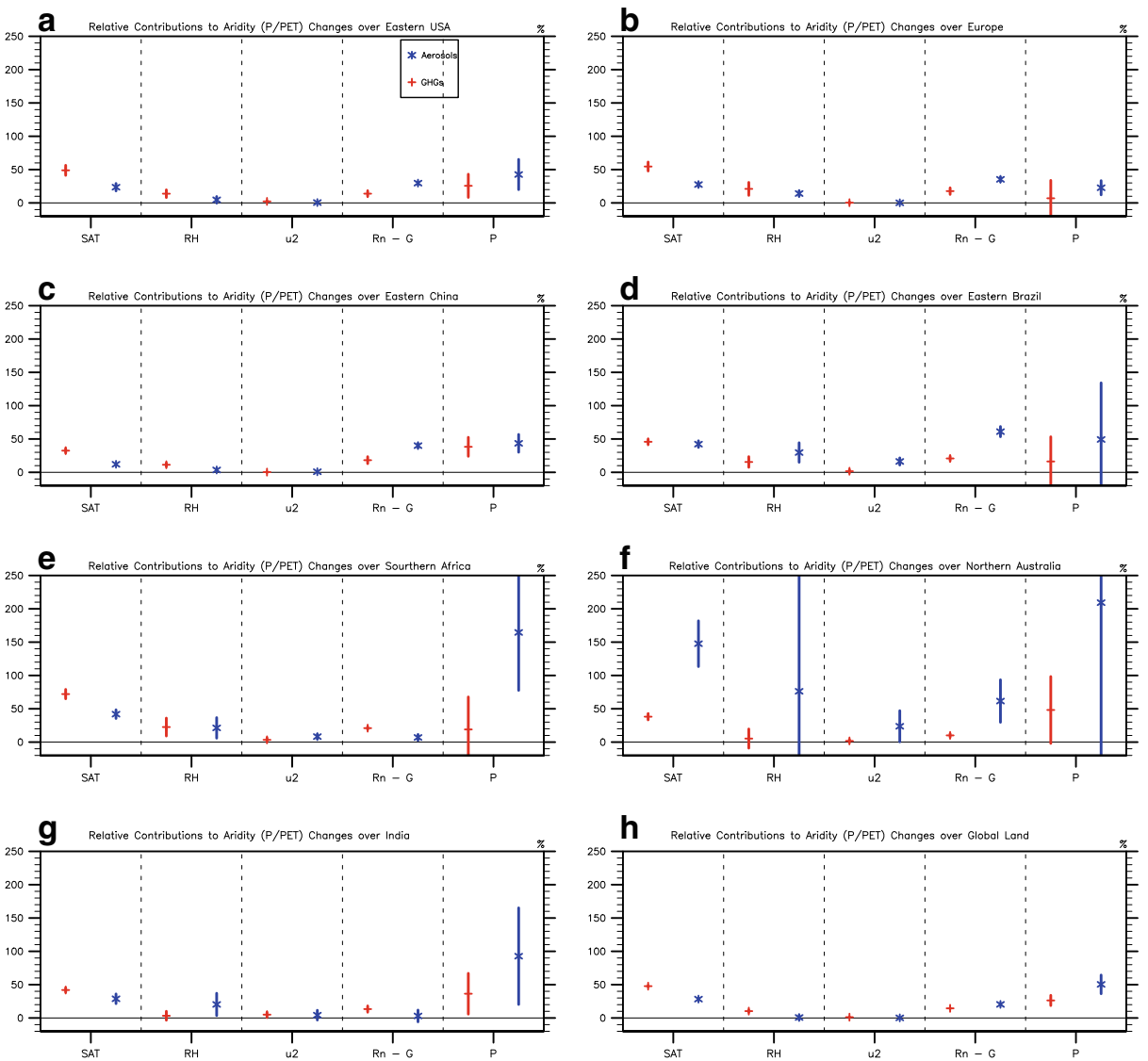

Fig. 5 Relative contribution of Surface Air Temperature (SAT), Relative Humidity (RH), Wind Speed at $2 \mathrm{~m}$ $\left(\mathrm{u}_{2}\right)$, Surface Available Energy $(\mathrm{Rn}-\mathrm{G})$ and Precipitation $(\mathrm{P})$ on the change in P/PET over seven study areas and global land. The red (blue) error bar denotes two standard deviation of GHGs (Aerosols). Note all relative contributions are displayed as positive numbers, regardless of the actual sign 
larger ensemble spread at regional scale is associated with the high variance of regional precipitation patterns, but all regions except Northern Australia and India have a significantly (larger than ensemble spread) smaller drying in the mitigation scenario (RCP4.5).

Reduction of aerosols is another forcing to future global change with a different time scale than GHG forcing. Four RCP scenarios all assume aerosol emissions decreases, which enhance the future GHG warming and increase precipitation. Here we show that aerosol changes have little impact on global land aridity, but may have significant effects at regional scale. This result has broad implication, because previous work has suggested that "volcanic" (geo-engineering) and dust aerosol changes would lead to global drought (Tilmes et al., 2013). In our model simulations, aerosols indeed lead to strong suppression of precipitation (Fig. 3d). However, aerosols induce a similar amount of PET and precipitation change over land, canceling out any change in P/PET.

In our simulations, aerosol decline contributes nearly a full degree of warming by 2100 in RCP8.5 and nearly half of the total increase in precipitation. These non-negligible aerosol effects on future temperature and precipitation have been noted by previous studies (e.g. Levy et al., 2013). To the best of our knowledge, however, the effects of GHG increases and aerosol decreases on future global P/PET have not been separated out before. Previous studies suggesting that future predicted climates are more arid (defined by P/PET) focused only on GHG effects.

The physical mechanism of GHG induced P/PET is mainly temperature-based (e.g. the evaporation rate increases with temperature and other factors do not compensate). Based on this mechanism, one would expect an aerosol-driven cooling to have similar effects on P/PET as a GHG-driven one, just with the opposite sign. Surprisingly, our study fails to detect any significant net impact of aerosol changes on P/PET, suggesting that future changes of P/PET in the model are entirely attributable to GHGs even though the temperature and precipitation change are not all due to GHGs. This result contradicts previous claims that aerosols will lead to aridity increases, which consider only the impact on precipitation and ignore that on evaporation. Our study is consistent with a previous study by Zhao et al. (2014) that looked at the impact of dust aerosols over semi-arid regions.

The sensitivity of T, P, PET and P/PET due to GHGs is consistent in sign and magnitude across regions, while the sensitivity due to aerosols varies between regions, because of the regional nature of the response to short-lived aerosol effects (Shindell et al., 2015). Therefore, conclusions focusing on the sensitivity of aridity to GHGs may not be applicable in $\mathrm{NH}$ regions of high aerosol loading and large aerosol perturbations.

There is relatively larger land warming $\left(1.5 \pm 0.1^{\circ} \mathrm{C} /{ }^{\circ} \mathrm{C}\right)$ due to aerosols than due to GHGs $\left(1.3 \pm 0.03{ }^{\circ} \mathrm{C} /{ }^{\circ} \mathrm{C}\right)$, due to larger aerosol loading over land. Since large land warming is the fundamental reason behind land P/PET decreases under GHG warming (Sherwood and Fu, 2014), the $25 \%$ larger land warming due to aerosols partly explains the larger PET sensitivity. Another contributor to larger PET sensitivity due to aerosols is the surface energy budget perturbation ( $\mathrm{Rn}-\mathrm{G})$, which is mainly from short-wave clear-sky changes. Because aerosols decrease surface temperature and also heat the atmosphere through direct absorption, aerosols lead to a reduction of precipitation. Over NH regions except India, the contribution through this energy term is even larger than that temperature. Part of this is coming from absorbing aerosols, which warm the surface (increasing PET) but block solar radiation reaching the surface (decreasing PET).

Overall, GHG mitigation may significantly reduce the projected drying. Mitigation of aerosols tends to lead to enhanced warming, which in turn generally increases PET. But it 
also leads to enhanced precipitation, so the net global effect on P/PET is small. Temperature term dominates the response to GHGs, while the response to aerosols is more complicated, and can vary regionally, due to differences in both P and PET. In this work, we have not explored the impact of different types of aerosols. Zhao et al. (2014) found the effects of dust aerosols are indiscernible in the expansion of arid and semi-arid areas on a global scale. In CESM1, most of aerosol effects on liquid clouds are due to $\mathrm{SO}_{4}$ (Gettelman et al., 2010), so it is likely $\mathrm{SO}_{4}$ is the major component of the aerosol impact we have analyzed. Although our large ensemble approach can quantify uncertainty due to model internal variability, the uncertainty associated with the model structure need further study.

Acknowledgments We thank three anonymous reviewers for their helpful comments. This study is in part supported by the NSFC Grants 41521004, 41275070 and 41405010, National Basic Research Program of China (2012CB955303), and the Fundamental Research Funds for the Central Universities (lzujbky-2015-k02). Y.X. was supported by a postdoctoral fellowship from the Advanced Study Programme (ASP) of National Center for Atmospheric Research (NCAR) and by the Regional and Global Climate Modeling Program (RGCM) of the U.S. Department of Energy's Office of Science (BER), Cooperative Agreement DE-FC02-97ER62402. Computing resources (ark:/85065/d7wd3xhc) were provided by the Climate Simulation Laboratory at NCAR's Computational and Information Systems Laboratory, sponsored by the National Science Foundation (NSF) and other agencies. The National Center for Atmospheric Research is supported by the U. S. National Science Foundation.

\section{Appendix A: Change in P/PET and contributions from changes in SAT, RH, $\mathbf{u}_{2}, \mathbf{R n}-\mathbf{G}$ and $P$}

Here we define $\mathrm{P} / \mathrm{PET}=\mathrm{g}\left(\mathrm{SAT}, \mathrm{RH}, \mathrm{u}_{2}, \mathrm{Rn}-\mathrm{G}, \mathrm{P}\right)$ (i.e. P over equation(1)), the subscripts " 0 " and "1" to represent the mean values for the different simulations, respectively.

To SAT: $\Delta(\mathrm{P} / \mathrm{PET}) \_\mathrm{SAT}=\mathrm{g}\left(\mathrm{SAT}_{1}, \mathrm{RH}_{0}, \mathrm{u}_{20}, \mathrm{Rn}-\mathrm{G}_{0}, \mathrm{P}_{0}\right)-\mathrm{g}\left(\mathrm{SAT}_{0}, \mathrm{RH}_{0}, \mathrm{u}_{20}, \mathrm{Rn}-\mathrm{G}_{0}\right.$, $\mathrm{P}_{0}$ ). The same method treat to $\mathrm{RH}, \mathrm{u}_{2}, \mathrm{Rn}-\mathrm{G}$.

To P: $\Delta(\mathrm{P} / \mathrm{PET}) \_\mathrm{P}=\mathrm{g}\left(\mathrm{SAT}_{1}, \mathrm{RH}_{1}, \mathrm{u}_{21}, \mathrm{Rn}-\mathrm{G}_{1}, \mathrm{P}_{1}\right)-\mathrm{g}\left(\mathrm{SAT}_{1}, \mathrm{RH}_{1}, \mathrm{u}_{21}, \mathrm{Rn}-\mathrm{G}_{1}, \mathrm{P}_{0}\right)$. Note the effects of precipitation on $\mathrm{P} / \mathrm{PET}$ is positive number when the other variables negative, so here we define the relative contribution by $\left|\mathrm{x}_{\mathrm{i}}\right| / \Sigma\left|\mathrm{x}_{\mathrm{i}}\right|$, not $\mathrm{x}_{\mathrm{i}} / \Sigma \mathrm{x}_{\mathrm{i}}$.

\section{References}

Allen RG, Pereira LS, Raes D, Smith M (1998) Crop evapotranspiration-guidelines for computing crop water requirements-FAO irrigation and drainage paper 56. FAO, Rome 300:6541

Clarke, L., Edmonds, J., Jacoby, H., Pitcher, H., Reilly, J., \& Richels, R. (2007). Scenarios of greenhouse gas emissions and atmospheric concentrations. US Department of Energy Publications, 6

Cook, B. I., Smerdon, J. E., Seager, R., \& Coats, S. (2014). Global warming and 21st century drying. Clim Dyn, 1-21

Dai A (2013) Increasing drought under global warming in observations and models (vol 3, pg 52, 2013). Nat Clim Chang 3(2):171-171. doi:10.1038/nclimate1811

Feng S, Fu Q (2013) Expansion of global drylands under a warming climate. Atmos Chem Phys 13(19):1008110094. doi:10.5194/acp-13-10081-2013

Fu Q, Feng S (2014) Responses of terrestrial aridity to global warming. J Geophys Res-Atmos 119(13). doi:10. 1002/2014jd021608

Gao Y, Li X, Leung LR, Chen D, Xu J (2015) Aridity changes in the Tibetan plateau in a warming climate. Environ Res Lett 10(3):034013

Gettelman A, Liu X, Ghan SJ, Morrison H, Park S, Conley AJ, Li JLF (2010) Global simulations of ice nucleation and ice supersaturation with an improved cloud scheme in the community atmosphere model. J of Geophys Res-Atmos:115. doi:10.1029/2009jd013797 
Huang, J., Yu, H., Guan, X., Wang, G., \& Guo, R. (2015). Accelerated dryland expansion under climate change. Nat Clim Chan

Huang J, Lin B, Minnis P, Wang T, Wang X, Hu Y, Ayers JK (2006a) Satellite-based assessment of possible dust aerosols semi-direct effect on cloud water path over east Asia. Geophys Res Lett 33(19). doi:10.1029/ 2006g1026561

Huang J, Wang T, Wang W, Li Z, Yan H (2014) Climate effects of dust aerosols over east Asian arid and semiarid regions. J Geophys Res-Atmos 119(19):11398-11416. doi:10.1002/2014jd021796

Huang JP, Minnis P, Lin B, Wang TH, Yi YH, Hu YX, Ayers K (2006b) Possible influences of Asian dust aerosols on cloud properties and radiative forcing observed from MODIS and CERES. Geophys Res Lett 33(6). doi:10.1029/2005gl024724

Hurrell JW, Holland MM, Gent PR, Ghan S, Kay JE, Kushner PJ, Marshall S (2013) The community earth system model a framework for collaborative research. Bull Am Meteorol Soc 94(9):1339-1360. doi:10. 1175/bams-d-12-00121.1

Kay JE, Deser C, Phillips A, Mai A, Hannay C, Strand G, Arblaster JM, Bates SC, Danabasoglu G, Edwards J, Holland M, Kushner P, Lamarque J-F, Lawrence D, Lindsay K, Middleton A, Munoz E, Neale R, Oleson K, Polvani L, Vertenstein M (2015) The Community Earth System Model (CESM) Large Ensemble Project: A community resource for studying climate change in the presence of internal climate variability. Bull Am Meteorol Soc 96:1333-1349. doi:10.1175/BAMS-D-13-00255.1

Klimont Z, Smith SJ, Cofala J (2013) The last decade of global anthropogenic sulfur dioxide: 2000-2011 emissions. Env Res Lett 8(014003). doi:10.1088/1748-9326/8/1/014003

Lambert FH, Allen MR (2009) Are changes in global precipitation constrained by the tropospheric energy budget? J Clim 22(3):499-517

Levy H, Horowitz LW, Schwarzkopf MD, Ming Y, Golaz JC, Naik V, Ramaswamy V (2013) The roles of aerosol direct and indirect effects in past and future climate change. J of Geophys Res: Atmos 118(10):4521-4532

Lin L, Gettelman A, Feng S, Fu Q (2015) Simulated climatology and evolution of aridity in the 21st century. J Geophys Res Atmos 120. doi:10.1002/2014JD022912

Lin L, Gettelman A, Xu Y, Fu Q (2016) Simulated responses of terrestrial aridity to black carbon and sulfate aerosols. J Geophys Res Atmos 121. doi:10.1002/2015JD024100

Liu X, Easter RC, Ghan SJ, et al. (2012) Toward a minimal representation of aerosols in climate models: description and evaluation in the community atmosphere model CAM5[J]. Geosci Model Dev 5:709-739

Meehl GA, Washington WM, Arblaster JM, et al. (2013) Climate change projections in CESM1 (CAM5) compared to CCSM4[J]. J Clim 26(17):6287-6308

Morrison H, Gettelman A (2008) A new two-moment bulk stratiform cloud microphysics scheme in the community atmosphere model, version 3 (CAM3). part I: description and numerical tests. J Clim 21(15):3642-3659

Nastos PT, Politi N, Kapsomenakis J (2013) Spatial and temporal variability of the aridity index in Greece. Atmos Res 119:140-152

Neale, R. B., Chen, C.-C., Gettelman, A., Lauritzen, P. H., Park, S., Williamson, D. L., Lamarque, J.-F. (2010). Description of the NCAR community atmosphere model (CAM 5.0). NCAR Tech. Note NCAR/TN-486+ STR

Penman HL (1948) Natural evaporation from open water, bare soil and grass. Proc R Soc Lond 193A:120-145. doi:10.1098/rspa.1948.0037

Ramanathan V, Crutzen P, Kiehl J, Rosenfeld D (2001) Aerosols, climate, and the hydrological cycle. Sci 294(5549):2119-2124

Riahi K, Rao S, Krey V, Cho C, Chirkov V, Fischer G, Rafaj P (2011) RCP 8.5-a scenario of comparatively high greenhouse gas emissions. Clim Chang 109(1-2):33-57. doi:10.1007/s10584-011-0149-y

Rosenfeld D, Lohmann U, Raga GB, O’Dowd CD, Kulmala M, Fuzzi S, Andreae MO (2008) Flood or drought: how do aerosols affect precipitation? Science 321(5894):1309-1313

Sanderson BM, Oleson KW, Strand WG, Lehner F, O’Neill BC (2015) A new ensemble of GCM simulations to assess avoided impacts in a climate mitigation scenario. Clim. Chang:1-16

Scheff J, Frierson DMW (2014) Scaling potential evapotranspiration with greenhouse warming. J Clim 27(4): 1539-1558. doi:10.1175/jcli-d-13-00233.1

Scheff J, Frierson DM (2015) Terrestrial aridity and its response to greenhouse warming across CMIP5 climate models. J Clim 28:5583-5600. doi:10.1175/JCLI-D-14-00480.1

Sheffield J, Wood EF, Roderick ML (2012) Little change in global drought over the past 60 years. Nat 491(7424):435-438

Sherwood S, Fu Q (2014) A drier future? Sci 343(6172):737-739

Shindell DT, Faluvegi G, Rotstayn L, Milly G (2015) Spatial patterns of radiative forcing and surface temperature response. Atmospheres, Journal of Geophysical Research

Shiogama H, Hanasaki N, Masutomi Y, Nagashima T, Ogura T, Takahashi K, Emori S (2010) Emission scenario dependencies in climate change assessments of the hydrological cycle. Clim Chang 99(1-2):321-329. doi: 10.1007/s10584-009-9765-1 
Shuttleworth WJ (1993) Evaporation. In: DR m (ed) handbook of hydrology, vol 4. McGraw-Hill Inc, pp. 1-4.53 Smith SJ, van Aardenne J, Klimont Z, Andres RJ, Volke A, Arias SD (2011) Anthropogenic sulfur dioxide emissions: 1850-2005. Atmos Chem Phys 11(3):1101-1116. doi:10.5194/acp-11-1101-2011

Stocker TF, Qin D, Plattner GK, Tignor M, Allen SK, Boschung J, Nauels A, Xia Y, Bex B, Midgley BM (2013) IPCC, 2013: climate change 2013: the physical science basis. Contribution of working group I to the fifth assessment report of the intergovernmental panel on climate change. Cambridge University Press

Taylor KE, Stouffer RJ, Meehl GA (2012) AN OVERVIEW OF CMIP5 AND THE EXPERIMENT DESIGN. Bull Am Meteorol Soc 93(4):485-498. doi:10.1175/bams-d-11-00094.1

Thornthwaite CW (1948) An approach toward a rational classification of climate. Geogr Rev:55-94

Tilmes, Simone, et al. (2013). The hydrological impact of geoengineering in the Geoengineering Model Intercomparison Project (GeoMIP). J of Geophys Res: Atmos 118.19 (2013): 11-036

Van Vuuren DP, Edmonds J, Kainuma M, Riahi K, Thomson A, Hibbard K, et al. (2011) The representative concentration pathways: an overview. Clim Chang 109:5-31

$\mathrm{Xu}$ Y, Lamarque JF, Sanderson BM (2015) The importance of aerosol scenarios in projections of future heat extremes. Clim Chang 1-14

Zhao, S., Zhang, H., Feng, S., \& Fu, Q. (2014). Simulating direct effects of dust aerosol on arid and semi-arid regions using an aerosol-climate coupled system. Int J of Climatol 